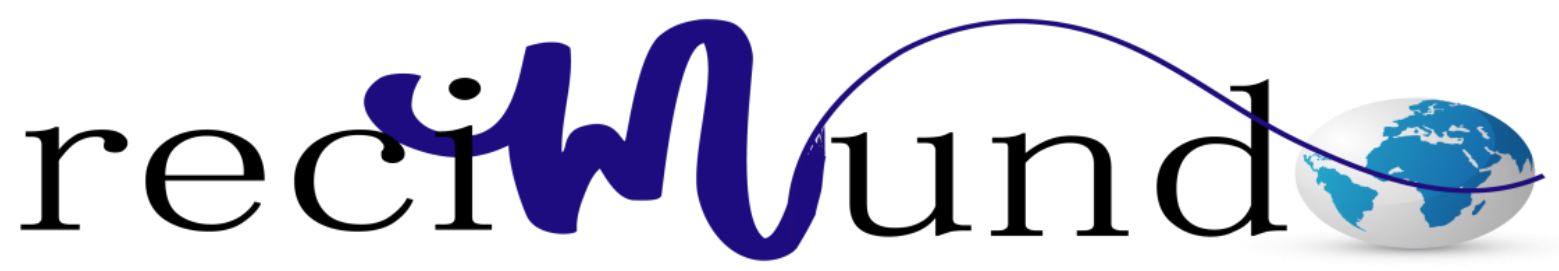

Revista Cientifica Mundo de la Investigación y el Conocimiento

Ana Isabel Pincay Durán ${ }^{\text {a }}$, Luz Teresa Cañarte Químis ${ }^{\text {b; }}$ Yahaira Grace Pincay

Durán ${ }^{c}$; Mercy Otilia Durán Vera ${ }^{\mathrm{d}}$

El derecho laboral de los inmigrantes extranjeros que están

momentáneamente en el Ecuador

The labor law of foreign immigrants who are

temporarily in Ecuador

Revista Científica Mundo de la Investigación y el Conocimiento. Vol. 2 núm.3, julio,

ISSN: 2588-073X, 2018, pp. 578-599

DOI: 10.26820/recimundo/2.(3).julio.2018.578-599

Editorial Saberes del Conocimiento

Recibido: 05/04/2018

Aceptado: 04/06/2018

Publicado: 30/07/2018

Correspondencia: luz.canarte@unesum.edu.ec

a. Magister en Gerencia en Seguridad y Salud en el Trabajo; Ingeniera Química; Universidad Estatal del Sur de Manabí; ana.pincayduran@ hotmail.com

b. Magister en Docencia mención Gestión en Desarrollo del Currículo; Diplomado en Autoevaluación y Acreditación Universitaria; Ingeniero Comercial; Universidad Estatal del Sur de Manabí; luz.canarte@ unesum.edu.ec

c. Magister en Tributación y Finanzas; Economista; Universidad Estatal del Sur de Manabí; yahaira.pincay82@gmail.com

d. Magister en Docencia Universitaria e Investigación Educativa; Diplomado en Autoevaluación y Acreditación Universitaria; Licenciado en Ciencias Sociales y Políticas; Profesora de Segunda Enseñanza; Abogado de los Juzgados y Tribunales de la Republica; Licenciada en Ciencias de la Educación

Esp. Química y Biología; Universidad Estatal del Sur de Manabí; mercy.duran@unesum.edu.ec 


\section{El derecho laboral de los inmigrantes extranjeros que están momentáneamente en el Ecuador}

Vol. 2, núm. 3., (2018)

Ana Isabel Pincay Durán; Luz Teresa Cañarte Químis; Yahaira Grace Pincay Durán; Mercy

Otilia Durán Vera

\section{RESUMEN}

El derecho laboral conocido también como derecho del trabajo o derecho social constituye una rama del derecho cuyas normas y principios jurídicos tienen por objeto la tutela del trabajo humano pudiendo ser realizado en forma libre, por cuenta ajena, en relación de dependencia y a cambio de una contraprestación. Para este estudio se ha tomado como referencia el caso de las personas extranjeras que están momentáneamente en el país debido a diferentes circunstancias; por ejemplo, en calidad de refugiados, es decir que, salieron de sus países de origen a consecuencia de guerras o a su vez en calidad de migrantes cuyo país de origen se encuentra en una difícil situación económica, por otro lado, también se analizó la migración en el país y la reacción de la población ante la llegada de extranjeros hacia nuestro territorio. Desde el ámbito legal, a través de la Constitución y la reciente Ley Orgánica de Movilidad Humana se han estipulado derechos y obligaciones de las personas extranjeras, en la cual se trata aspectos sobre el derecho al trabajo y a la seguridad social, sin embargo, en la mayor parte de casos tal normativa no se cumple a cabalidad ocasionando la presencia de estigmatización, rechazo y discriminación.

Palabras claves: Derecho laboral, Migrantes, Refugiados, Constitución, Ley Orgánica de Movilidad Humana. 


\section{El derecho laboral de los inmigrantes extranjeros que están momentáneamente en el Ecuador}

Vol. 2, núm. 3., (2018)

Ana Isabel Pincay Durán; Luz Teresa Cañarte Químis; Yahaira Grace Pincay Durán; Mercy Otilia Durán Vera

\section{ABSTRACT}

The labor law also known as labor law or social law is a branch of law whose rules and legal principles are aimed at the protection of human work can be performed freely, for others, in a relationship of dependence and in return for a consideration. For this study, reference has been made to the case of foreigners who are temporarily in the country due to different circumstances, for example as refugees, that is, they left their countries of origin as a result of wars or in turn as refugees. Migrants whose country of origin is in a difficult economic situation, on the other hand, also analyzed the migration in the country and the reaction of the population before the arrival of foreigners to our territory. From the legal sphere, through the constitution and the recent Organic Law of Human Mobility, rights and obligations of foreigners have been stipulated, in which aspects on the right to work and social security are discussed, however, in the In most cases such regulations are not complied with, causing the presence of stigmatization, rejection and discrimination.

Keywords: Labor Law, Migrants, Refugees, Constitution, Organic Law of Human Mobility. 


\section{El derecho laboral de los inmigrantes extranjeros que están momentáneamente en el Ecuador}

Vol. 2, núm. 3., (2018)

Ana Isabel Pincay Durán; Luz Teresa Cañarte Químis; Yahaira Grace Pincay Durán; Mercy

Otilia Durán Vera

\section{Introducción.}

La circulación de las personas entre países diferentes constituye parte integral de un entorno en proceso de globalización; con alrededor de 215 millones de migrantes a escala internacional (Álvarez, Giacolone, \& Sandoval, 2017), que en los actuales momentos habitan fuera de su país de origen, por lo tanto, la migración constituye también una respuesta a las crecientes desigualdades que se van registrando a nivel mundial.

La movilidad de las personas mediante las fronteras internacionales se remonta a la creación de las propias fronteras, y la vulnerabilidad de aquellas personas extranjeras no resulta una problemática reciente. Es importante diferenciar que la migración puede darse por diferentes situaciones, pudiendo ser para aprovechar las crecientes oportunidades del lugar de destino, por elección libre genuina y fundada, mientras que otras personas se ven obligados a desplazarse a diferentes países a consecuencia de la pobreza, falta de un trabajo estable, exclusión social a la cual se encuentran sometidos, violencia generalizada, persecución, violaciones de los derechos humanos, conflictos armados existentes, xenofobia y en porcentaje menor debido a la degradación del medio ambiente. En el lugar de destino, si bien muchas personas migrantes pueden vivir y trabajar en condiciones de seguridad y dignidad, en otros lugares la situación no es así, dada las complicaciones a las cuales se ven expuestos, por ejemplo: abuso, violencia, xenofobia, discriminación y explotación en el lugar de trabajo y en su vida privada, social, cultural y pública (Alto Comisionado de las Naciones Unidas para los Derechos Humanos, 2014). 


\section{El derecho laboral de los inmigrantes extranjeros que están momentáneamente en el Ecuador}

Vol. 2, núm. 3., (2018)

Ana Isabel Pincay Durán; Luz Teresa Cañarte Químis; Yahaira Grace Pincay Durán; Mercy Otilia Durán Vera

Desde el ámbito legal, a través de la Constitución aprobada durante el año 2008 y la reciente Ley Orgánica de Movilidad Humana aprobada en el año 2017 se han estipulado derechos y obligaciones de las personas extranjeras, en la cual se tratan aspectos de importancia sobre el derecho al trabajo y a la seguridad social, sin embargo, en la mayor parte de casos tal normativa no se cumple a cabalidad ocasionando la presencia de estigmatización, rechazo y discriminación.

\section{Desarrollo}

En Ecuador convergen varios procesos de movilidad humana. La migración y el refugio en el país han ido en aumento y esto ha generado también un dilema en el manejo de su política exterior. Ecuador en su Constitución afirma que ninguna persona puede ser considerada ilegal por su situación migratoria. Este principio afirma la utilización de la teoría de la ciudadanía universal como guía para la toma de decisiones en cuanto a movilidad humana por parte del gobierno (De la Torre, 2017).

\section{Refugio en el Ecuador}

Ecuador constituye el país dentro de la región que mayor número de refugiados ha acogido durante las últimas décadas, específicamente a partir del año 2000. Según información oficial del Alto Comisionado de Naciones Unidas para refugiados ACNUR (2018), hasta septiembre de 2016 Ecuador reconoció a 60.329 personas refugiadas. Otro dato interesante constituye el número total de personas que han solicitado el reconocimiento de status de refugiado en el país, siendo un número aproximado de 233.049 personas. 


\section{El derecho laboral de los inmigrantes extranjeros que están momentáneamente en el Ecuador}

Vol. 2, núm. 3., (2018)

Ana Isabel Pincay Durán; Luz Teresa Cañarte Químis; Yahaira Grace Pincay Durán; Mercy

Otilia Durán Vera

El Ecuador ratificó la Convención de Ginebra de 1951 sobre el Estatuto de los Refugiados y posteriormente su Protocolo de 1967. Con base a esto, el país se comprometió a acatar las disposiciones internacionales en materia de Derecho Internacional de Refugiados. Por otro lado, la Constitución Nacional del Ecuador aprobada en el año 2008 también garantiza y reconoce los derechos de refugio y asilo. Bajo este contexto, el país al momento de acoger a refugiados estaría dando cumplimiento con lo que estipula la Constitución además los compromisos internacionales inicialmente adquiridos. El proceso para tomar una decisión en cuanto a otorgar la condición a una persona como refugiada la toma el gobierno ecuatoriano mediante la Comisión para Determinar la Condición de Refugiado en el Ecuador. Dicho estamento tiene la participación de dos representantes del Ministerio de Relaciones Exteriores, además de un representante del Ministerio de Gobierno y representantes del ACNUR, sin embargo, estos últimos únicamente en calidad de observadores (Lozano, 2016).

A continuación, dentro de la tabla 1, se establece el marco legal que precautelan la seguridad de refugiados en el país, a través de leyes y acuerdos que fueron establecidos en diferentes años.

\section{Tabla 1. Marco legal}

\begin{tabular}{|l|l|}
\hline $\begin{array}{l}\text { Convención sobre el } \\
\text { Estatuto } \\
\text { Refugiados de 1951 }\end{array}$ & $\begin{array}{l}\text { Dicha convención fue efectuada en Ginebra entre el 2 y 25 de julio de } \\
1951 \text { en donde se estableció a que personas se les otorga el status de } \\
\text { refugiados, además las responsabilidades de los Estados involucrados } \\
\text { para garantizar el asilo. El país se adhirió el 17 de agosto de 1955. }\end{array}$ \\
\hline Protocolo de 1967 & $\begin{array}{l}\text { Sucesivo a la Convención de 1951, el Protocolo elimina barreras } \\
\text { geográficas y temporales de la Convención Protocolo de 1967 original, }\end{array}$ \\
\hline
\end{tabular}




\section{El derecho laboral de los inmigrantes extranjeros que están momentáneamente en el Ecuador}

Vol. 2, núm. 3., (2018)

Ana Isabel Pincay Durán; Luz Teresa Cañarte Químis; Yahaira Grace Pincay Durán; Mercy Otilia Durán Vera

\begin{tabular}{|c|c|}
\hline & $\begin{array}{l}\text { convirtiéndose en un instrumento mundial que garantiza la protección de } \\
\text { refugiados en cualquier lugar. Ecuador se adhirió } 6 \text { de marzo de } 1969 .\end{array}$ \\
\hline $\begin{array}{l}\text { Constitución } \\
\text { Nacional } \\
\text { Ecuador } 2008\end{array}$ & $\begin{array}{l}\text { La Constitución Nacional del Ecuador de } 2008 \text { garantiza: } \\
\text { - Art. 41: El reconocimiento de los derechos de asilo y refugio, } \\
\text { seguido con protección especial para garantizar el pleno ejercicio } \\
\text { de dichos derechos. Respeto al principio de no devolución, } \\
\text { asistencia humanitaria y jurídica. La no aplicación de sanciones a } \\
\text { personas solicitantes de refugio o asilo por ingreso o permanencia } \\
\text { irregular en el país. } \\
\text { - Art. 66: 14: Asistencia tanto humanitaria como jurídica. } \\
\text { - Art. 66:14: Pleno ejercicio de derechos y no devolución de } \\
\text { extranjeros cuando la vida, seguridad o integridad de los mismos } \\
\text { peligra. } \\
\text { Art. } 41 \text { y 393: Rechazo a todo tipo de discriminación, (xenofobia, } \\
\text { racismo). } \\
\text { Art. } 416: 5 / 6 \text { : Promueve la libre movilidad de personas en el } \\
\text { mundo con base al principio de ciudadanía universal. }\end{array}$ \\
\hline $\begin{array}{l}\text { Decreto Presidencial } \\
\mathrm{N}^{\circ} 1182,30 \text { Mayo } \\
\text { de } 2012\end{array}$ & $\begin{array}{l}\text { Basándose en el Art. } 41 \text { de la Constitución Nacional del Decreto Ecuador } \\
\text { de } 2008 \text {, La Convención sobre el Estatuto de Presidencial No Refugiados } \\
\text { de } 1951 \text { y el Protocolo de } 1967 \text {, el Decreto regula la aplicación y el } \\
\text { sistema de refugio en el país, especificando la manera en la que el Estado } \\
\text { ecuatoriano va a proceder en materia de refugio. }\end{array}$ \\
\hline
\end{tabular}

Fuente: Adaptado de De la Torre Cisneros (2017)

\section{Migración en Ecuador}

Ecuador constituye uno de los países que promueve la protección de los derechos humanos de los migrantes alrededor del mundo. Según el Ministerio del Interior (2018) en la actualidad los ciudadanos provenientes del exterior no necesitan visa para el ingreso al país por el tiempo de 90 días con fines turísticos a excepción de aquellos ciudadanos que provienen de países tales como China, Bangladesh, Afganistán, Etiopía, Nepal, Eritrea, Pakistán, Nigeria y 


\section{El derecho laboral de los inmigrantes extranjeros que están momentáneamente en el Ecuador}

Vol. 2, núm. 3., (2018)

Ana Isabel Pincay Durán; Luz Teresa Cañarte Químis; Yahaira Grace Pincay Durán; Mercy

Otilia Durán Vera

Somalia que si requieren de visado para su ingreso al país, en el caso de exceder los días establecidos por la Ley, es necesario realizar los trámites pertinentes adicionales en la Dirección de Extranjería del Ministro de Relaciones Exteriores a fin de extender el tiempo de permanencia y no quedar en calidad de indocumentados y ser deportados (Ministerio del Interior, 2018). Es importante, recalcar que Ecuador otorga una amplia gama de visas con el objetivo de regularizar la situación de aquellas personas que se hallen en situación migratoria. Dentro del marco del Buen Vivir, hoy conocido como Todo una Vida, la Constitución reconoce la migración como un Derecho, por lo cual se propone no identificar a ninguna persona como ilegal por su condición migratoria según el art. 40; y, en el contexto de las relaciones internacionales dentro del Título VIII, específicamente en el art. 46, se apela al principio de ciudadanía universal (Asamblea Nacional, 2017).

La nueva Ley Orgánica de Movilidad Humana en el Ecuador, se ha venido gestionando y busca edificar una legislación acorde con la Constitución aprobada en el año 2008 buscando garantizar el acceso a programas de desarrollo para migrantes con la finalidad de saldar la deuda social con estas personas y de esta forma garantizar el acceso a la educación, empleo, vivienda, salud y otros derechos que dentro de la Ley se encuentran contemplados (Ministerio de Relaciones Exteriores y Movilidad Humana, 2018).

\section{Ciudadanía universal dentro de la Constitución Nacional del Ecuador 2008}

La Constitución Nacional del Ecuador de 2008 dentro de uno de sus artículos acoge el principio de ciudadanía universal en relación a movilidad. Promoviendo una política migratoria inclusiva, en donde exista respeto a los derechos humanos de aquellas personas migrantes y 


\section{El derecho laboral de los inmigrantes extranjeros que están momentáneamente en el Ecuador}

Vol. 2, núm. 3., (2018)

Ana Isabel Pincay Durán; Luz Teresa Cañarte Químis; Yahaira Grace Pincay Durán; Mercy Otilia Durán Vera

refugiadas. Bajo este contexto, dentro del art. 416 de la Constitución se garantiza la ciudadanía universal, en la cual se establece la libertad de movilidad y que ninguna persona podrá ser considerada ilegal en el país. Convirtiéndose este principio en un paradigma nuevo introducido por el gobierno central con la finalidad de incentivar una libre movilidad sin fronteras (Asamblea Constituyente de Ecuador, 2015).

\section{Reacción de la población ecuatoriana ante la llegada de personas extranjeras}

En el instante que se forman asentamientos de poblaciones extranjeras es muy común observar como en ciudades consideradas grandes de forma inmediata se crea el rechazo y racismo hacia estas personas. Dado que, la ciudadanía ecuatoriana aún no está preparada para aceptar de forma positiva tanto la migración como el refugio de aquellas personas que ingresan al país en búsqueda de nuevas oportunidades. A pesar de esta realidad, resulta muy contradictorio el hecho de observar como la población es preferencial con ciertos migrantes y cruelmente racista con otros, dependiendo de su origen de procedencia o su condición migratoria (Zepeda \& Carrión, 2015). Ante esta problemática vigente la Organización de Hermanos Jesuitas con sede en el país efectuó un estudio, en el cual se levantó alrededor de diez mil encuestas en las nueve cedes con las que cuenta dentro del territorio nacional desde el año 2012 hasta el año 2015. Cabe destacar que, dentro de las encuestas aplicadas, el objetivo fue obtener información acerca de la condición migratoria de estos grupos de personas, situación en el país de origen, condiciones de vida en el Ecuador, discriminación y motivos de salida de su país (Organización de Hermanos Jesuitas, 2017). Los datos obtenidos indican la percepción que los ecuatorianos 


\section{El derecho laboral de los inmigrantes extranjeros que están momentáneamente en el Ecuador}

Vol. 2, núm. 3., (2018)

Ana Isabel Pincay Durán; Luz Teresa Cañarte Químis; Yahaira Grace Pincay Durán; Mercy Otilia Durán Vera

mantienen sobre las personas migrantes y refugiados que se hallan en el país. A continuación, dentro de las figuras siguientes se presentan en porcentajes dicha percepción.

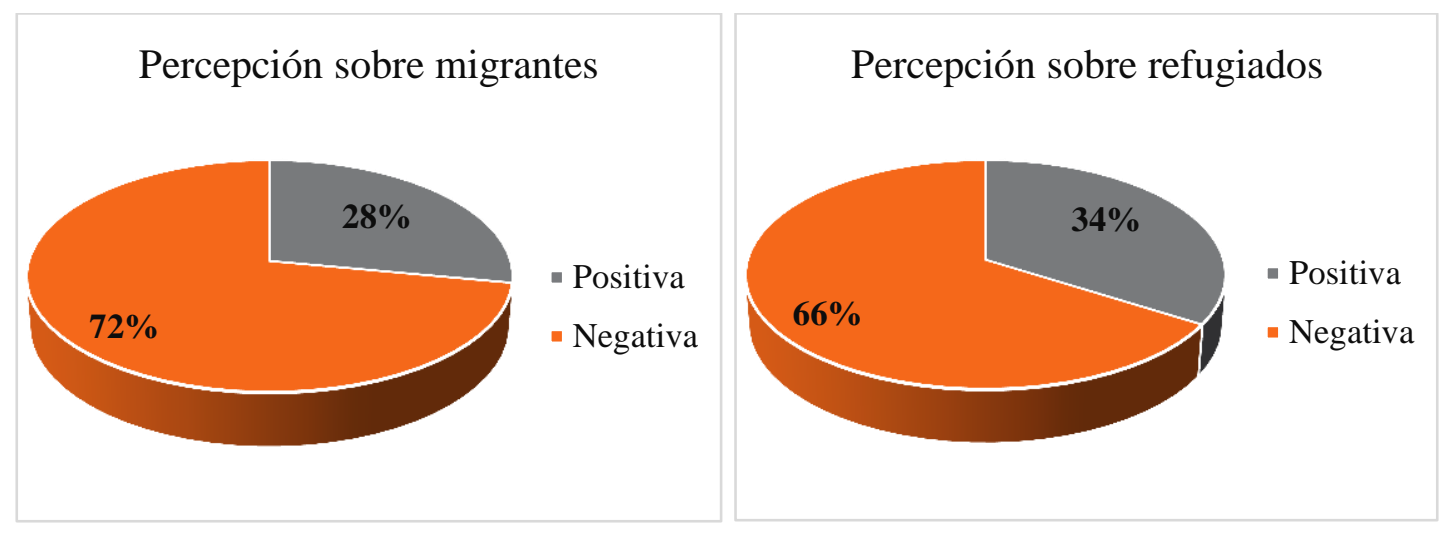

Figura 1. Percepciones sobre migrantes y refugiados

El rechazo y la estigmatización hacia migrantes de bajos recursos, así como también a refugiados no constituye un tema nuevo dentro del país y menos podría ser calificado como un caso aislado, sino más bien un caso recurrente, que ocurre a diario en las diferentes ciudades del Ecuador. Situación que en gran medida surge por la amenaza que estos grupos representan para los ciudadanos ecuatorianos especificadamente en el tema laboral, dado que la mano de obra de afuera es más barata que la nacional, además, otro dato importante constituye los motivos por los que estas personas son discriminadas en el país. Seguidamente, dentro de la figura 2, se presentan los resultados obtenidos de la información levantada por la Organización de Hermanos Jesuitas. 
El derecho laboral de los inmigrantes extranjeros que están momentáneamente en el Ecuador

Vol. 2, núm. 3., (2018)

Ana Isabel Pincay Durán; Luz Teresa Cañarte Químis; Yahaira Grace Pincay Durán; Mercy Otilia Durán Vera

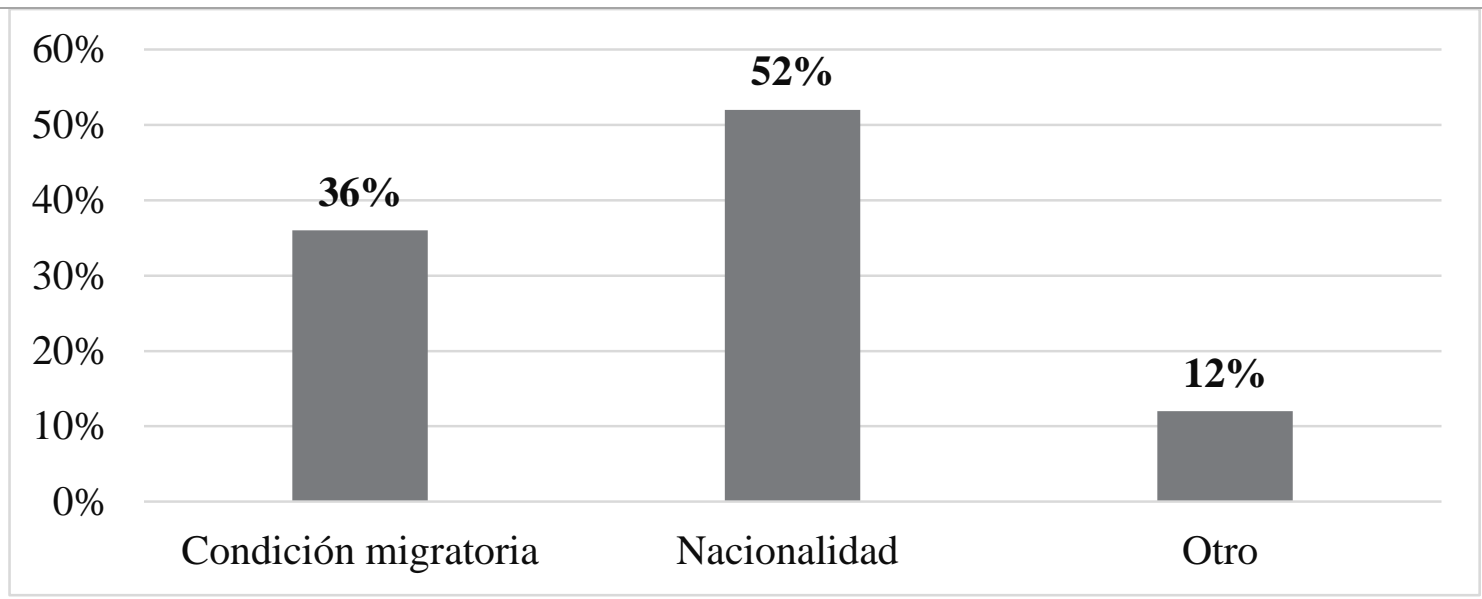

Figura 2. Motivos de la discriminación

Fuente: Adaptado de Organización de Hermanos Jesuitas (2017)

Como muestra la figura correspondiente, el principal motivo de discriminación hacia los ciudadanos extranjeros constituye su nacionalidad, es decir su país de origen y procedencia, otro aspecto importante a considerar es su condición migratoria. Bajo este escenario, la integración al país de los diferentes migrantes se ha visto limitada por la dificultad de acceso a educación, vivienda, empleo y salud. Acompañado con la estigmatización y el maltrato del que son víctimas este grupo de personas en el país. 


\section{El derecho laboral de los inmigrantes extranjeros que están momentáneamente en el Ecuador}

Vol. 2, núm. 3., (2018)

Ana Isabel Pincay Durán; Luz Teresa Cañarte Químis; Yahaira Grace Pincay Durán; Mercy

Otilia Durán Vera

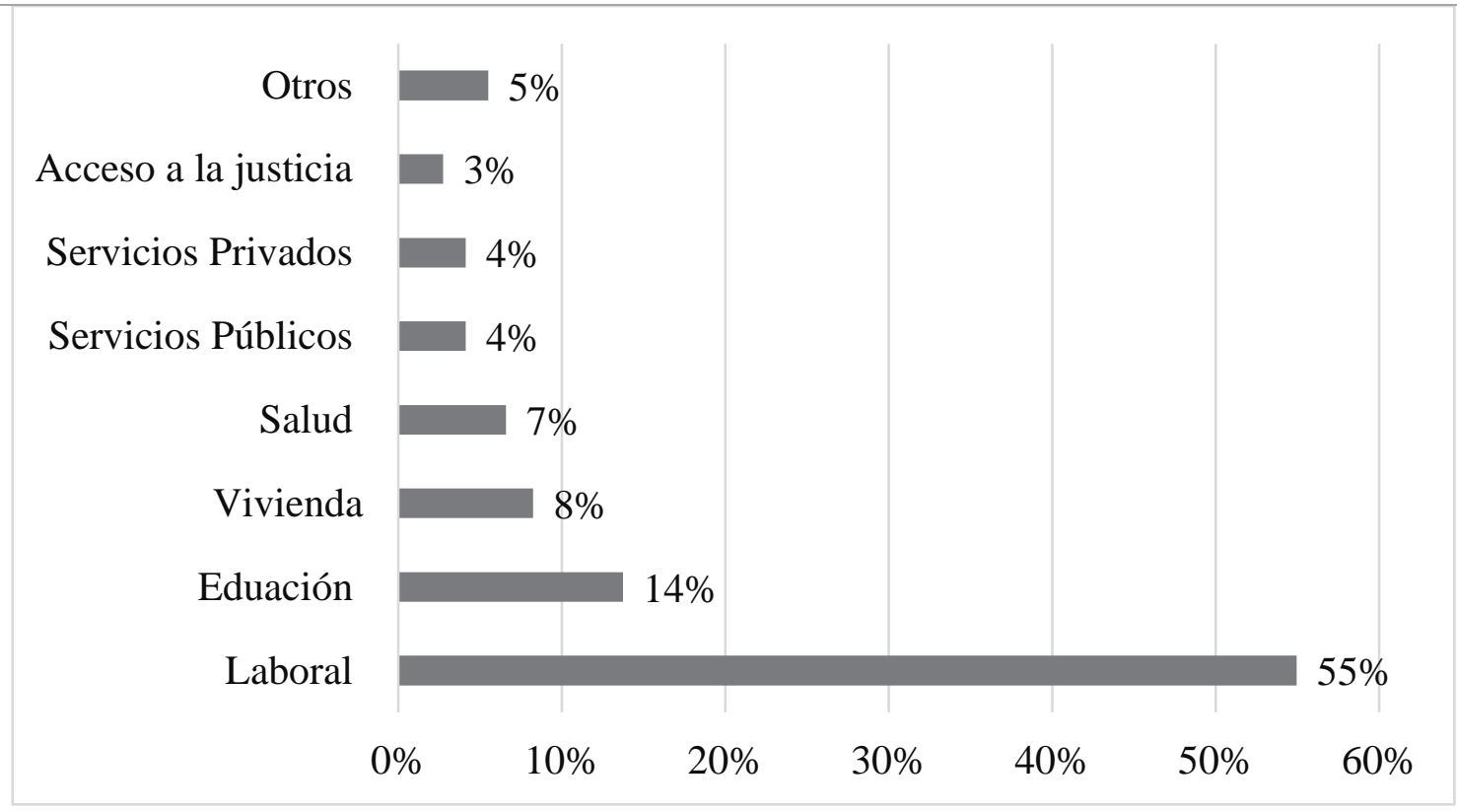

Figura 3. Sectores de discriminación

Como se muestra en la figura 3, la discriminación que se da en el país se da en diferentes niveles, siendo más notorio en ciertos campos que en otros. El sector en el cual se manifiesta mayor índice de discriminación en el Ecuador, es sin duda alguna dentro del ámbito laboral. Migrantes y refugiados son marginados y privados de la oportunidad de integrarse activa y dignamente a la sociedad.

La política migratoria de los últimos gobiernos a generado una serie de inconvenientes dado que en ciertas ocasiones se han abierto las fronteras, dando paso a extranjeros en cualquier condición migratoria, mientras que en otras se han cerrado al observar que la situación prácticamente se escapaba de las manos de las autoridades. Es importante resaltar, la iniciativa del país en intentar impulsar la ciudadanía universal, sin embargo, los altos flujos migratorios en ocasiones hacen que el Estado no abastezca dicha demanda, es decir, no brinde una ayuda 


\section{El derecho laboral de los inmigrantes extranjeros que están momentáneamente en el Ecuador}

Vol. 2, núm. 3., (2018)

Ana Isabel Pincay Durán; Luz Teresa Cañarte Químis; Yahaira Grace Pincay Durán; Mercy Otilia Durán Vera

oportuna ni necesaria tanto a migrantes como a refugiados lo que ha derivado en deportaciones hacia sus países de origen, además del rechazo y estigmatización por parte de la ciudadanía ecuatoriana. Es por ello, que la eliminación de fronteras al no solicitar las visas correspondientes para el ingreso a extranjeros no genera una ciudadanía universal por el contrario causa problemas tanto para las personas extranjeras como para las nacionales (Quiloango, 2015).

En el Ecuador migrantes provenientes de países norteamericanos y europeos son aceptados de forma rápida y más bien la ciudadanía nacional considera como un privilegio su presencia en el país. Un claro ejemplo de este escenario es aquel que se produce en la ciudad de Cuenca, en donde ciudadanos de Norteamérica se asentaron y la reacción de la población local fue positiva, Sin embargo, distinto es el escenario que viven aquellas personas migrantes de bajos recursos quienes a diario se enfrentan a rechazos, maltratos y abusos por tratar de buscar una oportunidad para mejorar su calidad de vida (De la Torre, 2017).

Claramente, se presentan dos escenarios completamente diferentes, el positivo un "buen migrante" y el negativo un "mal migrante" situación generada en gran medida por su condición social o a su vez por su origen de procedencia ocasionando diferencias abismales en el trato para uno y otro grupo. Resulta necesario, entender que para que pueda darse una verdadera ciudadanía universal es indispensable trabajar conjuntamente con las sociedades con el objetivo de entender que la situación migratoria de una persona no significa capacidades ni cualidades inferiores (Pisarello, 2014). Dado que estos migrantes constituyen un grupo vulnerable de bajos recursos, que por su situación al llegar a otro país sus derechos básicos son desconocidos, es decir, el acceso a una vida digna, acceso a la educación, un empleo seguro, una adecuada vivienda, por lo 


\section{El derecho laboral de los inmigrantes extranjeros que están momentáneamente en el Ecuador}

Vol. 2, núm. 3., (2018)

Ana Isabel Pincay Durán; Luz Teresa Cañarte Químis; Yahaira Grace Pincay Durán; Mercy

Otilia Durán Vera

que terminan siendo presa fácil de xenofobia, racismo y rechazo por parte del país al cual buscan acogerse, aumentando de esta manera la desigualdad social. Si bien es cierto que en su momento estas personas se encuentran dentro de los grupos vulnerables y necesitan de ayuda para insertarse positivamente dentro de la sociedad, este escenario no va a durar para toda su vida. A lo largo de la historia, los grupos minoritarios han sufrido explotación por el mero hecho de hallarse en una situación mala de forma momentánea que sin duda alguna ellos no eligieron, sin embargo, tanto los diferentes Estados como los ciudadanos en general deben dejar de lado los miedos y perjuicios y construir de esta forma sociedades verdaderamente equitativas.

Por otro lado, el reconocimiento de derechos a todas las personas dentro de una comunidad igualitaria resulta indispensable no solo para aquellas personas migrantes sino también para las personas nacionales. Es decir, al entregar garantías de derechos básicos y de desarrollo a los migrantes, estos van a tener a disposición herramientas necesarias para desenvolverse de forma digna dentro de la sociedad y dejaran en gran medida de ser relacionados directamente con delincuencia o como un problema social que los Estados están en la obligación de desterrar.

\section{Población de interés}

Los refugiados son personas que huyen de su país porque sus vida, libertad o seguridad han sido amenazadas por la presencia de una violencia generalizada, la agresión extrajera, los conflictos internos, la violación masiva de los derechos humanos u otros motivos que hayan perturbado gravemente el orden público (ACNUR, 2016). 


\section{El derecho laboral de los inmigrantes extranjeros que están momentáneamente en el Ecuador}

Vol. 2, núm. 3., (2018)

Ana Isabel Pincay Durán; Luz Teresa Cañarte Químis; Yahaira Grace Pincay Durán; Mercy Otilia Durán Vera

Según datos que maneja el Ministerio de Relaciones Exteriores y Movilidad Humana del Ecuador durante el año 2016, el número de refugiados colombianos reconocidos llegó a 57.325, de un total aproximado de 60.253 refugiados reconocidos (95.2\% del total); es decir, 2.928 representan personas refugiados de otras nacionalidades (4.8\%) mientras que, al término del año 2015, Ecuador registró un número aproximado de 233.049 solicitudes de asilo receptadas. De este número el $70 \%$ de las personas refugiadas en el país viven en áreas urbanas, mientras que la mayor parte del $30 \%$ restante permanecen cerca de la frontera, en zonas poco desarrolladas y aisladas, con enormes limitantes en relación a la infraestructura y servicios básicos (Castilla \& Escobar, 2017).

A continuación, dentro de la figura 4, según la ACNUR (2016) se expone el porcentaje de personas refugiadas por provincia, teniendo como principales hallazgos que las provincias de Pichincha y Sucumbíos presentan los mayores porcentajes con $26.80 \%$ y $23.66 \%$ respectivamente. 


\section{El derecho laboral de los inmigrantes extranjeros que están momentáneamente en el Ecuador}

Vol. 2, núm. 3., (2018)

Ana Isabel Pincay Durán; Luz Teresa Cañarte Químis; Yahaira Grace Pincay Durán; Mercy

Otilia Durán Vera

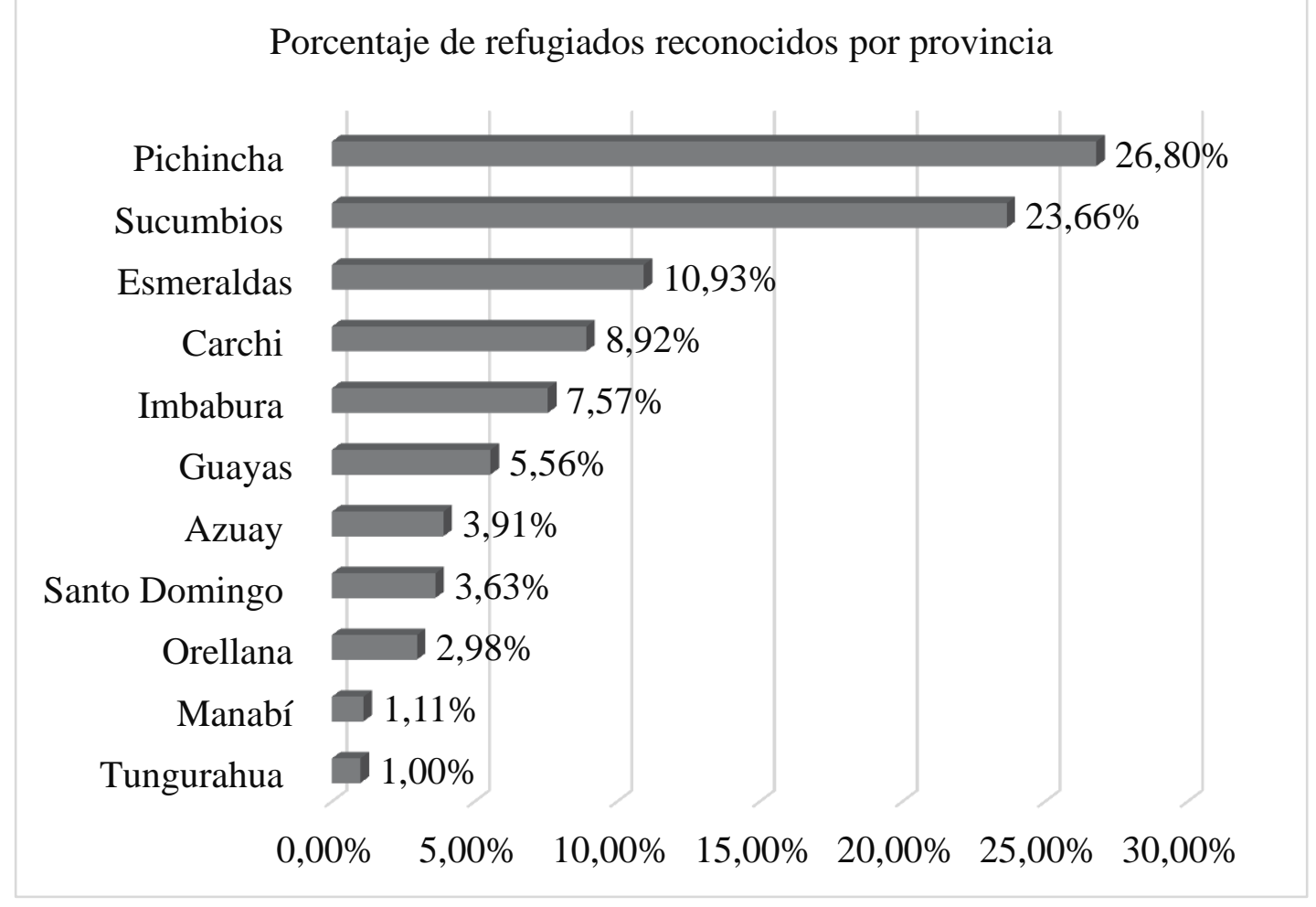

Figura 4: Porcentaje de refugiados reconocidos por provincia

\section{Personas extranjeras en el Ecuador}

\section{Definición, derechos y obligaciones}

A continuación, dentro de la tabla 2, de acuerdo a la Ley Organiza de Movilidad Humana dentro del capítulo III: personas extranjeras en el Ecuador, en la sección I, estipula la definición, derechos y obligaciones de aquellas personas que se encuentren en el país. 


\section{El derecho laboral de los inmigrantes extranjeros que están}

momentáneamente en el Ecuador

Vol. 2, núm. 3., (2018)

Ana Isabel Pincay Durán; Luz Teresa Cañarte Químis; Yahaira Grace Pincay Durán; Mercy Otilia Durán Vera

\section{Tabla 2. Marco legal para personas extranjeras en el Ecuador}

\begin{tabular}{|c|c|}
\hline Definición & $\begin{array}{l}\text { Artículo 42.- Persona extranjera en el Ecuador. La persona extranjera en el } \\
\text { Ecuador, es aquella que no es nacional del Estado ecuatoriano y se encuentra en } \\
\text { el territorio en condición migratoria de visitante temporal o residente. }\end{array}$ \\
\hline \multirow{3}{*}{ Derechos } & $\begin{array}{l}\text { Artículo 43.- Derecho a la libre movilidad responsable y migración segura. } \\
\text { Las personas extranjeras en el Ecuador tendrán derecho a migrar en condiciones } \\
\text { de respeto a sus derechos, integridad personal de acuerdo a la normativa interna } \\
\text { del país y a los instrumentos internacionales ratificados por el Ecuador. El } \\
\text { Estado realizará todas las acciones necesarias para fomentar el principio de la } \\
\text { ciudadanía universal y la libre movilidad humana de manera responsable. }\end{array}$ \\
\hline & $\begin{array}{l}\text { Artículo 44.- Derecho a solicitar una condición migratoria. Las personas } \\
\text { extranjeras tendrán derecho a solicitar una condición migratoria de conformidad } \\
\text { a lo establecido en esta Ley y su reglamento. Una vez concedida la condición } \\
\text { migratoria de residente se otorgará cédula de identidad. }\end{array}$ \\
\hline & $\begin{array}{l}\text { Artículo 45.- Derecho a la información migratoria. Las personas extranjeras } \\
\text { tendrán derecho a ser informadas de los requisitos y trámites necesarios para su } \\
\text { movilidad y la obtención de una condición migratoria, previo a su ingreso al }\end{array}$ \\
\hline
\end{tabular}




\section{El derecho laboral de los inmigrantes extranjeros que están momentáneamente en el Ecuador}

Vol. 2, núm. 3., (2018)

Ana Isabel Pincay Durán; Luz Teresa Cañarte Químis; Yahaira Grace Pincay Durán; Mercy

Otilia Durán Vera

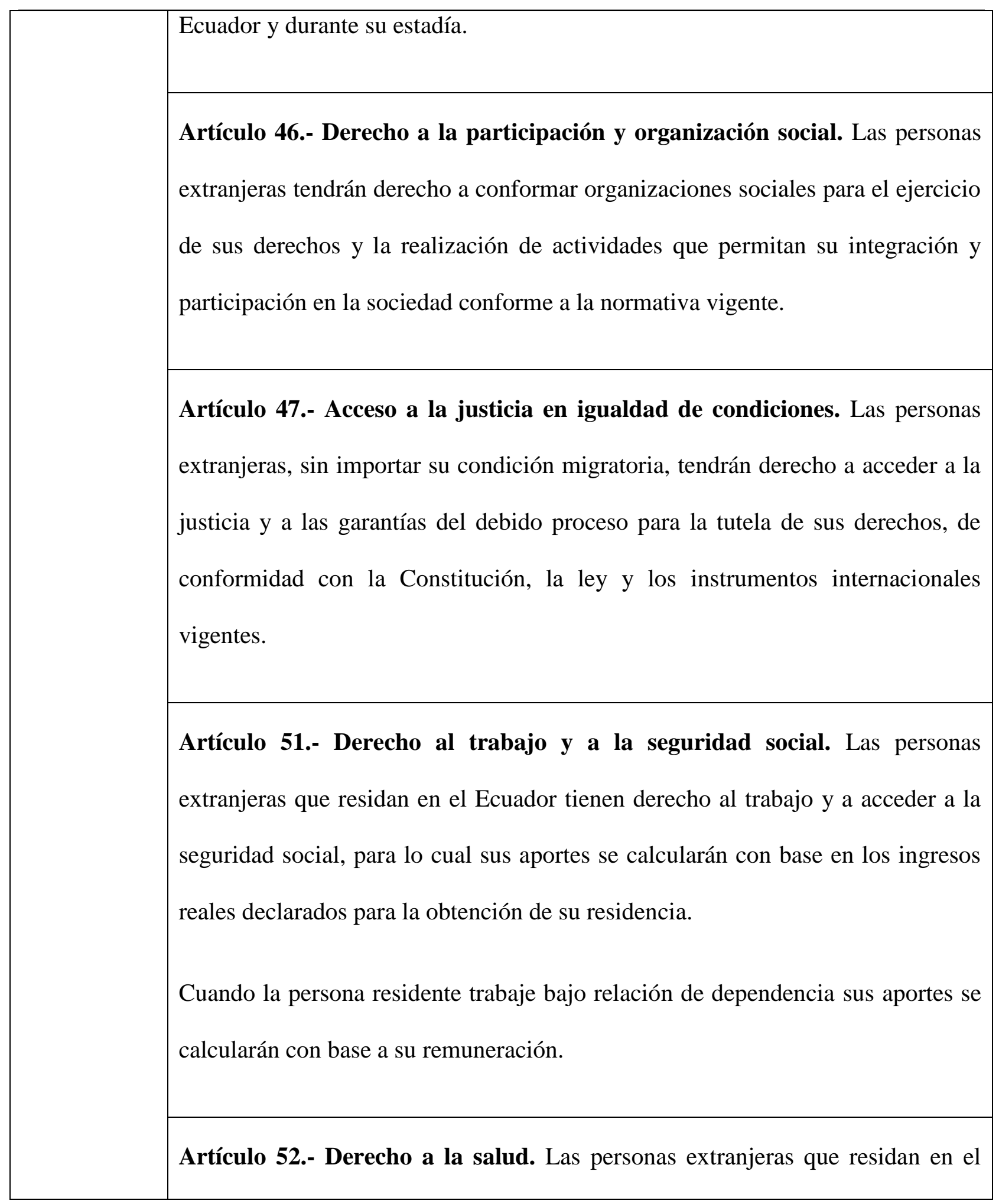




\section{El derecho laboral de los inmigrantes extranjeros que están momentáneamente en el Ecuador}

Vol. 2, núm. 3., (2018)

Ana Isabel Pincay Durán; Luz Teresa Cañarte Químis; Yahaira Grace Pincay Durán; Mercy Otilia Durán Vera

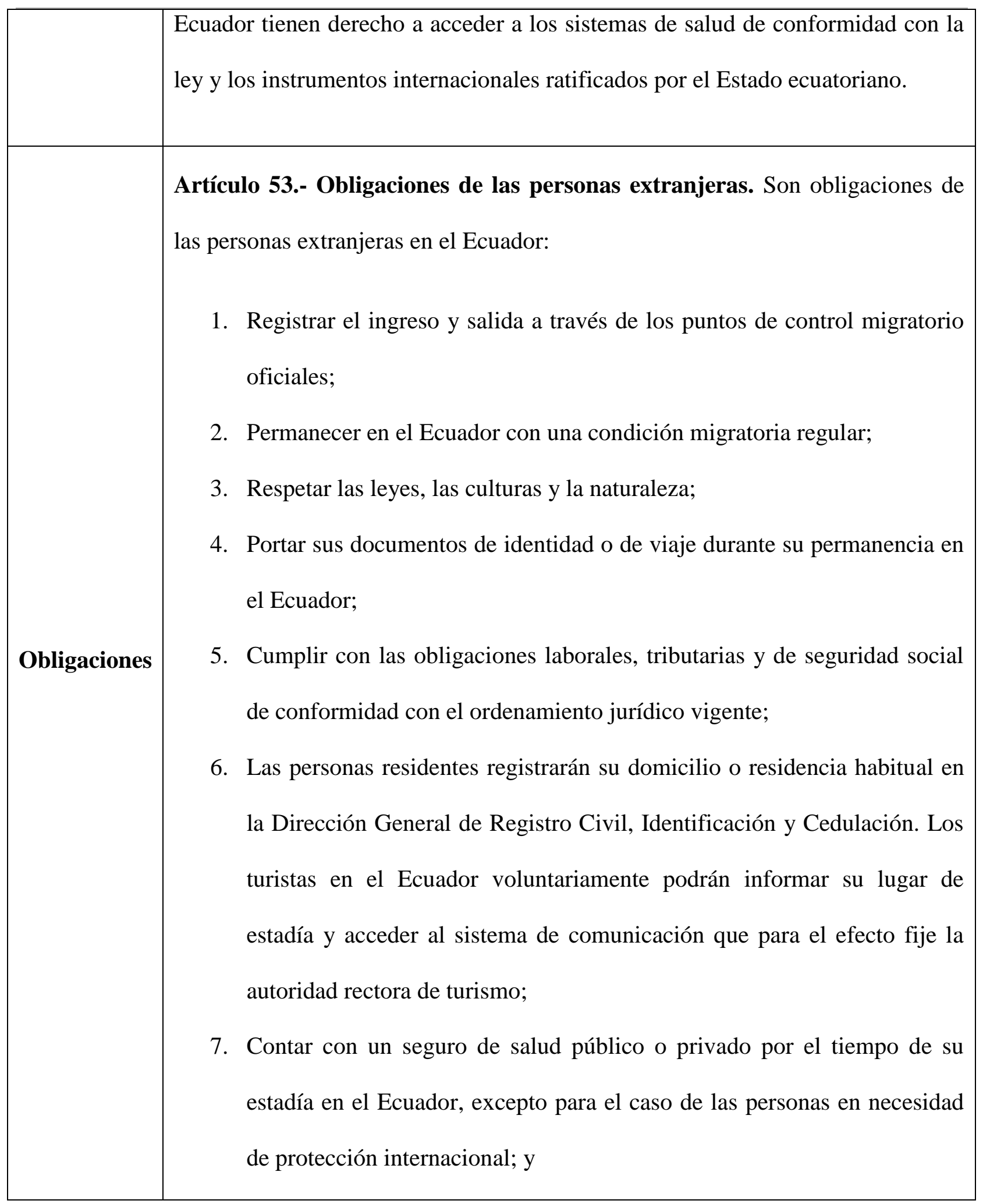




\section{El derecho laboral de los inmigrantes extranjeros que están momentáneamente en el Ecuador}

Vol. 2, núm. 3., (2018)

Ana Isabel Pincay Durán; Luz Teresa Cañarte Químis; Yahaira Grace Pincay Durán; Mercy

Otilia Durán Vera

\begin{tabular}{|l|l|}
\hline & 8. Las demás previstas en la ley. \\
\hline
\end{tabular}

Fuente: Adaptado de Asamblea Nacional (2017) "Ley Orgánica de Movilidad Humana"

\section{Conclusiones.}

El Ecuador necesita acoger tanto a refugiados como migrantes de manera integral, sin discriminación y estigma. Es decir, el trato debe ser igualitario para todos los extranjeros sin dar importancia a su condición migratoria. Po lo tanto, de ninguna forma se puede favorecer a migrantes por su condición económica y procedencia ni tampoco restar importancia a aquellos migrantes cuyo origen sea de países que se encuentran en difícil situación y extrema pobreza. En consecuencia, el país aún no se encuentra preparado para ser un Estado diverso que acepte a todos sus habitantes por igual. Dada la existencia en gran medida de xenofobia, racismo y discriminación hacia los refugiados y migrantes.

Es importante hacer una diferenciación entre refugiado y migrante, el primero abandona su país de origen a causas de guerra o de sus ideas políticas o religiosas, mitras que los migrantes abandonan su país origen en búsqueda de mejores oportunidades a fin mejorar su calidad de vida, sin embargo, existe la posibilidad de regresar a su país de origen en el momento que así lo decidan dado que aún se encuentran bajo la protección de su Estado.

En relación a las condiciones laborales a las cuales se ven expuestos tanto refugiados como migrantes es difícil para la mayor parte de este grupo vulnerable dado que el sector en el cual se registra mayor índice de discriminación en el país, es el ámbito laboral dado que, estas 


\section{El derecho laboral de los inmigrantes extranjeros que están momentáneamente en el Ecuador}

Vol. 2, núm. 3., (2018)

Ana Isabel Pincay Durán; Luz Teresa Cañarte Químis; Yahaira Grace Pincay Durán; Mercy Otilia Durán Vera

personas son marginados y privados de la oportunidad de integrarse de forma activa y dina dentro de la sociedad.

A pesar que tanto la Constitución aprobada en el año 2008 y la reciente Ley Orgánica de Movilidad Humana estipulan derechos y obligaciones de las personas extranjeras en el país, en la mayoría de casos estos aspectos no llegan a cumplirse ocasionando la presencia de discriminación, maltrato, estigma y rechazo.

\section{Referencias Bibliográficas}

ACNUR. (2016). ACNUR en Ecuador - Abril de 2016. Quito.

Alto Comisionado de las Naciones Unidas para los Derechos Humanos. (2014). Migración y derechos humanos: mejoramiento de la gobernanza basada en los derechos humanos de la migración internacional. Ginebra. Retrieved from http://www.ohchr.org/Documents/Issues/Migration/MigrationHR_improvingHR_ReporSPt. pdf

Alto Comisionado de las Naciones Unidas para los Refugiados. (2018). Tendencias globales desplazamiento forzado en 2017. Madrid.

Álvarez, R., Giacolone, R., \& Sandoval, J. M. (2017). Globalización, integración y fronteras en Amerrica Latina. Biblioteca Digital Andina. Universidad de los Andes. Retrieved from http://www.comunidadandina.org/bda/docs/VE-INT-0001.pdf

Asamblea Constituyente de Ecuador. (2015). Constitución de la República del Ecuador (Vol. 53). https://doi.org/10.1017/CBO9781107415324.004

Asamblea Nacional. (2017). Ley Orgánica de Movilidad Humana. Quito.

Castilla Villanueva, C. A., \& Escobar Chávez, M. D. (2017). Análisis de conflictos en Medio Oriente y sus consecuencias para el Ecuador. Universidad de los Hemisferios.

De la Torre Cisneros, E. (2017). Haitianos entre el refugio y la migración irregular: movilidad humana en el cuador y sus efectos en la Sociedad. Universidad de las Américas.

Lozano León, L. (2016). Efectos y negociaciones en torno al sujeto refugiado/a a propósito de la población refujiada en Ecuador. Facultad Latinoamericana de Ciencias Sociales. 


\section{El derecho laboral de los inmigrantes extranjeros que están momentáneamente en el Ecuador}

Vol. 2, núm. 3., (2018)

Ana Isabel Pincay Durán; Luz Teresa Cañarte Químis; Yahaira Grace Pincay Durán; Mercy

Otilia Durán Vera

Ministerio del Interior. (09 de Agosto de 2018). Ecuador promueve política migratoria inclusiva y de respeto a los DDHH. Obtenido de https://www.ministeriointerior.gob.ec/ecuadorpromueve-politica-migratoria-inclusiva-y-de-respeto-a-los-ddhh-2/\#

Ministerio de Relaciones Exteriores y Movilidad Humana. (2018). Plan Nacional de Movilidad Humana. Quito. Retrieved from http://www.cancilleria.gob.ec/mecanismo-ecuatoriano-deemisiones-netas-evitadas-se-presenta-en-reunion-de-expertos-en-bruselas/

Organización de Hermanos Jesuitas. (Julio de 2017). Servicio Jesuita a Refugiados-Ecuador (SJR-EC). Obtenido de http://www.jesuitas.ec/servicio-jesuita-a-refugiados-ecuador-sjr-ec/

Pisarello, G. (2014). Derechos sociales e inmigración: razones para una comunidad de iguales. Vniversitas, 110, 13-60.

Quiloango, S. (2015). Políticas públicas migratorias en el Ecuador. Friedrich Ebert Stiung, 1-32. Retrieved from http://library.fes.de/pdf-files/bueros/quito/07897.pdf

Zepeda, B., \& Carrión Mena, F. (2015). Las Américas y el Mundo: Ecuador 2014. (FLACSOEcuador, Ed.). Quito. 